УДК 82І.І6І.І.о

ББК $83.3(2 \mathrm{Poc}=\mathrm{Pyc}) 6$
МУЗЫКАЛЬНОЕ МИРООЩУЩЕНИЕ

В РОМАНЕ А.Ф. ЛОСЕВА

«ЖЕНЩИНА-МЫСЛИТЕЛЬ»

(c) 2018 г. Дж. Римонди

Пармский Государственный Университет,

Парма, Италия

Институт мировой литературы

им. А.М. Горького Российской академии наук, Москва, Россия

Дата поступления статьи: 27 июня 2017 г. Дата публикации: 25 марта 2018 г.

DOI: I0.22455/2500-4247-20I8-3-I-I4O-I53

Аннотация: В статье рассматривается роль музыки в контексте художественной прозы А.Ф. Лосева I930-х и І940-х гг. Основные идеи его философии музыки представлены путем анализа отношений между писателем и философом. Особое внимание уделяется выражению философских идей в романе «Женщина-мыслитель», в котором противопоставление рассудочной мысли и антиномическо-жизненного знания проявляется в форме дуализма «музыкального» и «немузыкального», как два способа отношения к сущности. В романе определение специфики музыкального мироощущения получает художественное воплощение в трагической судьбе пианистки Радиной, в образе которой раскрываются глубокие размышления о смысле жизни и о духовном состоянии современности.

Ключевые слова: философская проза А.Ф. Лосева, музыкальный миф, музыкальное мироощущение, «Женщина-мыслитель», автобиографизм, философия музыки.

Информация об авторе: Джорджия Римонди - PhD, Пармский Государственный Университет, Via Università, I2, 43I2I Parma PR, Италия, аспирант, Институт мировой литературы им. А.М. Горького Российской академии наук, ул. Поварская, д. 25 а, г2Іо69 г. Москва, Россия.

E-mail: giorgia.rimondi@gmail.com 


\section{MUSICAL OUTLOOK IN ALEXEY LOSEV'S NOVEL THE WOMAN-THINKER}

(C) 2018. G. Rimondi

This is an open access article distributed under the Creative Commons Attribution 4.0 International (CC BY 4.0)
University of Parma,

Parma, Italy

A.M. Gorky Institute of World Literature

of the Russian Academy of Sciences,

Moscow, Russia

Received: June 27, 2017

Date of publication: March 25, 2018

Abstract: This article discusses the role of music in the context of A.F. Losev's philosophical prose of the I930's and I940's. Describing the key ideas of Losev's philosophy of music, the essay presents Losev as both the writer and the philosopher and analyzes the relationship between these two facets of his work. It pays particular attention to the way philosophical ideas are conveyed in the novel The Woman-Thinker where the opposition of rational thought and antinomical knowledge emerges in the form of a binary of the "musical" and the "non-musical," as two modes of attitude to the being. In the novel, the specificity of the musical worldview is embodied in the tragic fate of the pianist Radina whose character reveals a deep reflection on the meaning of life and the spiritual state of contemporaneity.

Keywords: A.F. Losev's philosophical prose, musical myth, musical worldview, The WomanThinker, autobiographism, philosophy of music.

Information about the author: Giorgia Rimondi, $\mathrm{PhD}$, University of Parma, Via Università, I2, 43I2I Parma PR, Italy, PhD student, A.M. Gorky Institute of World Literature of the Russian Academy of Sciences, Povarskaya 25 a, I21069 Moscow, Russia.

E-mail: giorgia.rimondi@gmail.com 
В ранней статье «Русская философия» (I9I8) А.Ф. Лосев, характеризируя тип русской мысли и ее основные направления, писал о глубокой взаимосвязи философии и литературы, что, по его мнению, является отличительной чертой русской художественной прозы. Мысль о философичности русской литературы не нова - в русской философии проблема рассматривалась С.С. Аверинцевым, В.В. Бибихиным, П.П. Гайденко и другими; также интересные наблюдения можно найти у литературоведов и искусствоведов - А.А. Потебни, С.Л. Выготского, М.М. Бахтина.

Размышляя о специфике русской мысли, Лосев отмечает ее тесную связь с литературной формой:

С этой «жизненностью» русской философской мысли связан тот факт, что изящная литература является колыбелью самобытной русской философии. В прозаических произведениях Жуковского и Гоголя, в творчестве Тютчева, Фета, Льва Толстого, Достоевского, Максима Горького часто обсуждаются основные философские проблемы, разумеется, в их специфически русском, исключительно практическом, ориентированном на жизнь виде. И решаются эти проблемы таким образом, что всякий непредвзятый и компетентный судья назовет эти решения не только «литературными» или «художественными», но философскими и гениальными [6, с. I88-189].

Художественные произведения А.Ф. Лосева продолжают это направление русской литературы, связанной с попыткой решения главных вопросов бытия. 
Лосевское литературное творчество (стихи, рассказы, повести, роман) относится к г930-І940 гг. (период «подполья», поскольку Лосеву было запрещено цензурой заниматься философией), однако долгое время Лосев-писатель был обойден вниманием критиков и литературоведов потому, что его рассказы начали издавать только в начале І990-х гг. К тому же, по мнению Е.А. Тахо-Годи, Лосева долго не признавали как прозаика именно из-за того, что ко времени публикации прозы он уже был признанным философом, так что его литературная работа рассматривалась как «опыт» философа. Помимо этого, как свидетельствовала А.А. Тахо-Годи, Алексей Федорович при жизни никогда о литературных работах не вспоминал и никому их не показывал, рукописи были обнаружены в его домашнем архиве только в г989 г., уже после кончины философа.

Литературное наследие Лосева включает роман «Женщина-мыслитель» (1933-І934) и несколько рассказов и повестей: «Мне было г9 лет» (1932), «Переписка в комнате» (г932), «Театрал» (1932), «Встреча» (I933), «Трио Чайковского» (І933), «Завещание о любви, Метеор, Седьмая симфония» (г933), «Из разговоров на Беломорстрое» (б. д.), «Епишка» (б. д.), «Вранье сильнее смерти» (б. д.), «Жизнь» (194I). Сначала некоторые рассказы были опубликованы в разных журналах и отдельных изданиях, потом они вошли в сборники «Жизнь. Повести, рассказы, письма» (СПб., І993), «Мне было г9 лет. Дневники, письма, проза» (М., І997) и «Я сослан в XX век...» (М., 2002).

Лосевское литературное творчество тесно связано с его ранними теоретическими сочинениями, в нем нашли отражение основные положения его философских трудов г920-х гг. В рассказах и повестях чисто философские идеи переплетаются с художественным сюжетом, следовательно, трудно провести грань между философским и собственно художественным. Многие мотивы и образы (противопоставление романтизма и реализма, идея откровения через искусство, размышления о кризисе современной культуры, онтологическое понимание музыки и пр.), впервые воплощенные в философских работах, получат дальнейшее развитие в прозе, что дает право говорить о «философской прозе» Лосева.

Тот факт, что лосевская проза относится к 1930-1940 гг., когда мыслитель уже был приговорен к «философскому» молчанию, приводит к выводу о том, что отражение философских идей в рассказах совсем не случайно. 
Произведения мыслителя, как философские, так и художественные, образуют собой единое целое по цели и содержанию. Лосевская проза отражает философский мир писателя не только непосредственно, через «философские» монологи и диалоги персонажей, но и опосредованно, через систему образов, благодаря чему достигается глубокая взаимосвязь философских мыслей и формы их выражения в художественном тексте. Как отмечал сам Лосев, говоря о своем романе, «было бы чрезвычайно странно подходить с художественной оценкой к сочинению, состоящему на $1 / 4$ из философских рассуждений, да и остающаяся $1 / 4$, по самому замыслу автора, имеет тут гораздо больше идейное, чем просто художественное значение» [5, с. I42].

Однако присутствие автора в тексте не ограничивается лишь изложением философских взглядов автора, а раскрывается в биографическом следе, который есть в тексте. При этом следует отметить, что лосевская проза писалась «в стол», не для читателя, а для себя, поэтому часто герой является прямым выражением авторской позиции, о чем свидетельствуют мелкие автобиографические детали, разбросанные по тексту. Разные рассказы («Встреча», «Метеор», «Из разговоров на Беломорстрое», «Трио Чайковского») и роман «Женщина-мыслитель» объединяет наличие в них одного и того же лица, Николая Вершинина, охарактеризованного одинаково: он любитель музыки, ученый, вынужденный бросить философскую работу, который влюбляется в женщину-артистку (пианистку или певицу), - и все это характерные черты самого автора.

Говоря об автобиографических чертах автора-философа в лосевской художественной прозе, следует упомянуть о том, что в основе романа «Женщина-мыслитель» лежит встреча с М.В. Юдиной, ставшая значительным событием в жизни Лосева. Со знаменитой пианисткой, которая увлекалась философией, он встречался два раза: в апреле г930, за несколько дней до ареста, и зимой г933 г., после возвращения в Москву [9, с. II6-II7]. Окончив роман, Лосев читал его в двух домах, а также отправил его Юдиной. Однако, к его удивлению, она обвинила его в клевете, поскольку у пианистки из «Женщины-мыслителя» есть ряд недостатков - она истерична, избалованна, непостоянна. Хотя Лосев отрицал, что Юдина послужила прототипом Радиной, А. Кузнецов подчеркивал параллель между радинским окружением и бахтинским невельским кружком, к которому принадлежала и она. 
$<$...> если А.Ф. Лосев и метил в какую-то «цель», написав эту прозу, то ею могла быть прежде всего, по-видимому, не близкая ему «карнавальная» обстановка вокруг тех или иных имен и явлений культуры 20-х годов, в том числе в философских кругах, в частности в Невельском кружке М.М. Бахтина, к которому принадлежала и М.В. Юдина. Пародируя (или продолжая?) в своей прозе «мениппеи» К. Вагинова («Козлиная песнь» и «Труды и дни Свистонова» тогда уже были изданы), он направил ее жало против не соответствующей строгости его платонизма и шеллингианства «эстетической вольности» бахтианцев, с которыми, по всей вероятности, он пересекся. Так и возникли в романе «Женщина-мыслитель» едва скрытые образы М.М. Бахтина (Бахианчик), Л.В. Пумпянского (Пупа), В.Н. Волошинова (Бетховенчик), К.К. Вагинова (Максим Максимович) и так далее [I].

Однако вопрос о полемике Лосева с «невельцами» остается открытым, поскольку нет сведений о том, что Лосев был знаком с ними. Е.А. Тахо-Годи отмечает, что «до написания Женщины-мыслителя Лосев ничего о “невельцах” не знал или их существование его мало занимало - на них нет ни сносок в его философских трудах, ни намека в прозаических вещах, созданных до романа. Кто мог рассказывать о юдинском окружении Лосеву в конце г933 года? “Подельник” Лосева, А.Б. Салтыков - дядюшка юдинского жениха К. Салтыкова? Или лосевский друг по ГАХН М.И. Каган? Но трудно предположить, чтобы Кагана давал иронические отзывы о Бахтине и его кружке» [II, с. 77-78].

Несмотря на то что Лосев был знаком с Юдиной и, вероятно, образ женщины-артистки с ней связан, доказать это сложно. Трудно поверить, что основная цель «Женщины-мыслителя» заключается в карикатуре на артистку, тем более что в письме к Юдиной от I7 февраля I934 г. сам Лосев признавал, что некоторые черты героини списаны не с женщины, а с мужчины, «с одного крупнейшего русского писателя, одного из основателей и столпов символизма» [5, с. I43] ${ }^{\text {I }}$ К тому же Е.А. Тахо-Годи считает, что для понимания лосевской прозы биографические вехи не столь существенны, подчеркивая этим, что жизненный материал не должен помешать читателю увидеть философский смысл лосевской прозы [го, с. 38]. Итак, автобиографизм у Лосева связан не только с фактами, но и с эстетическими структурами, мировоззрением и экзистенциальными ценностями автора-мыслителя.

I E.А. Тахо-Годи полагает, что речь идет о Вяч. Иванове. 
Разочарованный реакцией Юдиной Лосев решил не публиковать роман. Он писал ей I6 февраля I934 г.: «Никому этой рукописи я и не давал и теперь ради Вас, не дам. Я читал в двух домах только І-ю главу, да и то с опущением конца (угрозы разоблачения “секретов”, связанные по сюжету с последующим)» [5, с. I45].

Одной из главных тем, которая занимает особое место как в теоретических работах, так и в прозе в целом является определение сущности музыки и ее роли в жизни человека. Предпочтение Лосевым музыкального искусства объясняется, кроме известных биографических обстоятельств (Лосев был скрипачом и в І920-е гг. занимался музыкальной эстетикой при ГАХН, ГИМН и Московской Консерватории), тем, что оно является безо́бразным выражением смысла. Именно в этом мыслитель усматривает сходство между музыкой и бытием:

Все прочие искусства есть уже внешнее выражение музыки. Всякое не музыкальное искусство создает образ, стоящий между внешним миром и музыкой. <...> Тут есть устойчивая образность, которой совсем лишена музыка. Музыка есть в этом смысле полная безобразность, обнаженная душа искусства, самое сердце бытия, лишенное внешнего тела. В музыке слышится пульсация первозданных основ искусства. <...> Кто пленен музыкой, тот захвачен самыми глубокими корнями своих чувств, тому ведома тайна прорицания самых основ духовно-душевной жизни [2, с. 65].

В музыке человек испытывает не только чисто философское, но и жизненное, духовное откровение. В этой сфере, происходящей из «ощущения бесформенной хаотической качественности бытия», раскрывается трагический характер жизни, напоминающий известное ницшеанское определение «рождении трагедии из духа музыки» [7, с. 320]. Отсюда лосевская критика рассудочного (чисто логического) миросозерцания, противопоставленного мироощущению. Термин мироощущение употребляется не случайно. Лосев проводит четкую границу между мироощущением («мирочувствием») и миросозерцанием [4, с. 782-783]. Первое - это непосредственное и интуитивное видение сущности, второе же - рационалистическое понимание мира.

Подобная концепция лежит в основе романа «Женщина-мыслитель», где в образе пианистки Радиной воплощается конфликт двух мироощущений - музыкального и немузыкального. 
Роман издавался в журнале «Москва» (I993, № 4, 5, 6, 7), а в полном объеме он был опубликован лишь в 2002 г. во втором томе сборника «Я сослан в XX век...». В основе сюжета романа - воспоминание героя Николая Вершинина о встрече на концерте с известной пианисткой Марией Радиной. Наблюдая ее в повседневной жизни, в кругу знакомых, Вершинин понимает, что ее жизнь не соответствует ее гениальности. Она живет в коммуналке, ее окружение пошлое, она истерична, капризна. Вместе с двумя другими поклонниками Радиной он собирается «спасать» пианистку и вырвать ее из пошлого окружения. Однако спасти Радину ему не удается - пианистка погибнет от руки одного из ее поклонников.

События романа разворачиваются на фоне размышлений о связи действительности и искусства. В самом начале романа пианистка изображается как персонификация музыкальной стихии. У нее особое, почти мистическое вдохновение 2 , в ней «нет никакой расчетливости», она мыслит не рассудочно, аналитически, а музыкально [2, с. го]. Герой считает, что в Радиной воплощены черты «музыкального мироощущения», и именно поэтому ее можно назвать «мыслителем». Далее в романе изображение персонажа Радиной доходит до степени магического и чудесного, она «ведьма», «страшная»; ее музыка «магична», «раскрывает само бытие».

В образе Радиной дается обобщенный портрет мыслителя. В «мистериальных ощущениях» пианистки герой усматривает черты философской мысли. Здесь интересно отметить параллель с личным опытом автора. В дневнике от 26 мая І9I4 г. Лосев так описывает философское откровение, которое он испытал после посещения концерта Скрябина: «Приезжавши с концерта, <...> произошло, кажется, откровение через Гуссерля. Кажется, я понял его феноменологию» [2, с. 430]. В «невыразимости» и «бесформенности» заключается специфика музыкального знания, в отличие от рассудочного: «...музыка не изображает вещи <..> Никаким словом, никаким понятием нельзя ознаменовать музыку» [8, c. II5]. В музыке нет никакой законченной оформленности, она прямо

\footnotetext{
2 Попутно отметим, что в письме к Юдиной от г6 февраля 1934 г. Лосев выражает аналогичную мысль применительно к знаменитой пианистке: «В Вашей игре я ощутил свою родную стихию мысли, скрытые - может быть, даже неясные Вам самой - философские постижения, завораживающую глубину и размах прозрения, которые я находил только у крупнейших философов» [2, с. I46].
} 
изображает сущности: «музыка содержит в себе образ стремящегося бытия» [8, c. II5]. Музыка хаотична, рождается из становления противоположных начал (рождение и уничтожение), и человек, который слушает ее, брошен в чистую бытийственность. В лосевской прозе музыка всегда связана с переживанием героя, она то вызывает воспоминания, то сопровождает чувства, то меняет его душевное настроение. В рассказе «Мне было I9 лет» молодой человек, влюбленный в певицу, теряет ощущение реальности на концерте. Таким же образом герой «Трио Чайковского» после слушания арии из оперы «Франческа да Римини» Рахманинова ощущает действие «тайной силы» над собой [8, с. I63].

Музыкальный опыт служит откровением высшей, подлинной реальности. Переживая музыку, герой соприкасается с тайной жизни:

Только в музыке оживляется, одухотворяется и одушевляется внешний мир. Пропадает безличие мира, исчезает его косность и механизм, и мы начинаем слышать как бы самый пульс мировой и всемирно-божественной жизни. Только музыка открывает человеку тождество его душевных движений с процессами объективной действительности [2, с. 84].

В «Женщине-мыслителе» размышление о музыкальном искусстве передается в разговоре персонажей, рассуждающих о роли музыки в жизни. Как писал сам Лосев, говоря о структуре своего романа, «речь Телегина об отношении музыки и жизни (а это ведь целая большая статья!), где поставлен кардинальный вопрос всего мировоззрения <...> речь Вершинина о молитве и умном делании (а это ведь тоже целая большая статья!), где решается вопрос о двояком пути восхождения и, вместе с тем, вопрос о философской значимости двух великих культур» [5, с. I49].

Проблема эстетического бытия человека обсуждается в речи персонажей. С одной стороны, музыка - фикция, платоновская «копия копии», не только не имеющая ничего общего с действительностью, но и даже отрешенная от последней. Эта позиция выражается в речи студента Телегиным:

Искусство не есть творчество самой жизни. Искусство есть только творчество жизненных форм. Подлинное искусство не заинтересовано в жизни. $<. .>$ Эстетическое бытие не есть бытие реальности, физической или психиче- 
ской. Эстетическое бытие - нейтрально в отношении всякого бытия. <... > уже по одному тому, что искусство есть искусство, оно есть некий уход от жизни, некое оставление ее на произвол судьбы. Искусство создает то, чего нет, не-сушее. Самое реалистическое и насквозь натуралистическое искусство все-таки не есть жизнь, а только изображение жизни. <...> Если человек только и живет искусством, это значит, что он находится всецело во власти несуществующего. Он творит и мыслит несуществующее [2, с. 62-63].

Телегину возражает Воробьев, который предупреждает о мире, лишенном музыки:

- Жизнь была бы тюрьмой, - читал он, - если бы не было искусства. <...> Искусство - воплощает идеи, материализует чувства, осуществляет мечту, делает телесным то, чего едва только могут касаться люди своим воображением. <...> Искусство живет совпадением всего идеального и реального, синтезом бесконечного и конечного, тождеством возвышенного и житейски-обыкновенного. В искусстве нет ничего теоретического, отвлеченного, условного, выдуманного, фиктивного. <...> оно - человеческая жизнь в своем конкретном явлении [2, с. 82].

Лосевская антитеза искусства и действительности находит свое яркое воплощение в образе Радиной. В героине персонифицирована несовместимость музыки и действительности, ее жизнь явно не соответствует ее музыкальной личности. После встречи героя с Радиной на концерте автор дает портрет ее бытовой жизни, в котором она изображается как обыкновенная женщина, мещанка, окруженная пошлыми поклонниками. Тем не менее сам автор уточняет, что «Радина изображена запутавшейся, - но совсем не мелкой (это я много раз подчеркиваю), а только запутавшейся и опустившейся» [5, с. I47].

Изображения Радиной-мыслителя и Радиной-женщины совершенно не соответствуют друг другу. Речь не идет просто о теме падшей женщины-артистки, жизнь на сцене которой отличается от ее повседневной жизни. Через личную драму автор изображает более глубокий раскол. Как подчеркивает сам Лосев, сцены первого посещения пианистки Вершининым «задуманы как контраст к I-й главе» [5, с. I43]. Пианистка как бы разделена надвое, она потеряла смысл существования, не признает своего гения и не 
раз выражает намерение бросить музыку, которая ее «сгубила» и «проглотила». В разговорах Радиной с Вершининым (alter ego Лосева) о смысле музыки автор старается показать, как отказ от признания главенствующей роли искусства для жизни приводит к опустошению внутреннего мира человека: «...музыкант есть выродившийся, падший, внутренне потерянный человек. $<. .>$ Радина закрыта от мира. Только в минуты ее вдохновения за фортепиано - можно одним глазом заглянуть в это ослепительное царство чудес и тайн, которые ведомы Радиной» [2, с. 67-69].

Отметим, что человек-артист в лосевской прозе страдает оттого, что он не мог объединить искусство и жизнь. Это также поднимает вопрос о природе гения и о его нравственной свободе, который обсуждается Воробьевым, одним из поклонников пианистки: «Гений и любовь не нуждаются в дисциплине. <...> Артист сам себе закон. На нем мы учимся свободе» [2, с. 83]. Этому Телегин возражает, что «трудно музыканту быть личностью <..> великие откровения музыки <...> невозможно реально воплотить и - остаться живым» [2, с. 7I]. Мистическое переживание артиста иллюстрирует противопоставление музыкального и немузыкального миропонимания, художественного и рассудочного.

В романе «Женщина-мыслитель» этот вопрос также рассматривается с точки зрения оппозиции музыки и современности. Контраст между двумя планами жизни Радиной (образ великого музыканта и падшей женщины, романтическое и реалистическое изображение) символизирует контраст между двумя планами бытия в «немузыкальном» обществе. Иными словами, образ Радиной воплощает в себе пропасть, возникшую в современном обществе между личностью и миром. Мир, в котором живут лосевские персонажи, движется к нигилизму, «надвигается новая культура, где этот абсолютизированный человеческий субъект будет повергнут в прах и где весь его романтизм, вся его значимость будет перенесена на внеличную стихию <...> И музыка перестанет удовлетворять человека так же, как перестало удовлетворять умное делание...» [2, с. 79].

Отсюда возникает лосевская оценка современности как процесса и результата мифологического «хаоса» в сознании человека, которая уже высказывалась в «Диалектике мифа» (І930). Абсолютизация субъекта современной эпохи привела к уничтожению личности, абсолютный миф был разрушен и разделен на ряд отдельных (относительных) мифов, которые, однако, никак не могут заменить первый. Итак, роман также можно прочи- 
тать на философском уровне как осознание невозможности совмещения этих фрагментов мифа. Не случайно герой представляется как тот, кто пытается спасти пианистку, но ему это не удается.

Все эти вопросы выявляют связь между писателем и мыслителем. Философия и художественная сфера составляют теоретический аппарат и общий контекст творчества Лосева. Они связаны единством замысла, тем и идей. И в прозе, и в теоретических трудах проявляется целостный замысел, призванный осветить отдельные философские аспекты. Художественный мир не только продолжает и возобновляет темы теоретических трудов, но и перерабатывает их и передает по-другому. Это обусловлено тем, что, по Лосеву, сферы познания не существуют отдельно друг от друга, а каждая передает фрагмент мировоззрения. Философия, музыка и литература отличаются только по способу передачи смысла. Уже в «Музыке как предмете логики» (1927) Лосев посвятил одну из глав «музыкальному мифу», где он писал: «..эти страницы <...> должны явиться мифологическим закреплением нашего отвлеченного анализа и опытным описанием того, как из океана алогической музыкальной стихии рождается логос и миф» [3, с. 470]. Подлинное познание мира дается не теоретически, а эстетически, знание через искусство не менее значительно, чем дискурсивное (логическое).

В романе следует выделить еще один аспект. Как уже отмечалось, лосевское осмысление музыки в теоретическом плане в І920-х гг. (в «Музыке как предмете логики», «Диалектике художественной формы», «Очерке о музыке») находит продолжение в литературных произведениях I930-х гг. Однако в конце І920-х гг. Лосев, по собственному признанию, перестал заниматься музыкой [5]. Причину этого мыслитель открыто не назвал, но, судя по содержанию текстов, происходит своего рода переоценка роли музыки и искусства в целом. В этом смысле следует понимать один из главных лейтмотивов лосевской прозы - сближение музыки и молитвы: оба опыта обеспечивают доступ к ноуменальному миру, при этом не менее реальному, чем мир явлений: «Есть тайная связь между откровениями мысли и внутренним отвержением себя, аскетизмом» [2, c. I6]. Однако в письме к Юдиной Лосев писал: «Я не скрываю от Вас, что музыка, да и Вы сами - для меня сейчас только результат моей слабости, как слабеет монах на тяжелом подвиге и вместо молитв иной раз требует утешения в леденцах» [5, с. I53]. 
Можно предположить, что пересмотр роли музыки привел Лосева к осознанию того, что над музыкой есть высшая область, где звучит «музыка самого бытия человека» [2, с. 77]. Истинное счастье и спасение можно найти только в религиозной сфере, в жизни души. Если применять эту точку зрения к образу Радиной, которой не удается примирить музыкальный и духовной восторг и даже понять значение музыкально-душевной сферы, становится понятным, что ее попытка найти смысл жизни обречена на провал. Возможно, через «музыкальный миф» своего романа автор стремился показать, как мир, лишенный музыки и потерявший связь с подлинным бытием, движется к расколу человеческой души.

\section{Список литературы}

Кузнецов А. Узрение существа музыки при посредстве естества женского и безумия артистического. URL: http://magazines.russ.ru/novyi_mi/1994/6/knobozoz.html (дата обращения: 28.03.2016).

Лосев А.Ф. Женщина-Мыслитель // Лосев А.Ф. «Я сослан в XX век...»: в 2 т. / под ред. А.А. Тахо-Годи; сост. и коммент. А.А. Тахо-Годи, Е.А. Тахо-Годи, В.П. Троицкого. М.: Время, 2002. Т. 2. С. 7-I4I.

3 Лосев А.Ф. Музыка как предмет логики // Лосев А.Ф. Форма. Стиль. Выражение / сост. А.А. Тахо-Годи; общ. ред. А.А. Тахо-Годи и И.И. Маханькова. М.: Мысль, г995. C. $405-583$. Лосев А.Ф. О мировоззрении Эсхила // Лосев А.Ф. Форма. Стиль. Выражение. М.: Мысль, 1995. С. 78I-876.

5 Лосев А.Ф. Приложение к роману Женщина-мыслитель // Лосев А.Ф. «Я сослан в $\mathrm{XX}$ век...»: в 2 т. / под ред. А.А. Тахо-Годи; сост. и коммент. А.А. Тахо-Годи, Е.А. Тахо-Годи, В.П. Троицкого. М.: Время, 2002. Т. 2. С. І42-162.

6 Лосев А.Ф. Русская философия // Лосев А.Ф. На рубеже эпох: Работы гіг-х начала г920-х годов / общ. ред. и коммент. А.А. Тахо-Годи, Е.А. Тахо-Годи,

В.П. Троицкого; сост. Е.А. Тахо-Годи, В.П. Троицкий. М.: Прогресс-Традиция, 2015. C. $188-189$.

7 Лосев А.Ф. Строение художественного мироощущения // Лосев А.Ф. Форма. Стиль. Выражение / сост. А.А. Тахо-Годи; общ. ред. А.А. Тахо-Годи и И.И. Маханькова. М.: Мысль, 1995. С. 297-320.

8 Лосев А.Ф. Трио Чайковского // Лосев А.Ф. «Я сослан в ХХ век...»: в 2 т. / под ред. А.А. Тахо-Годи; сост. и коммент. А.А. Тахо-Годи, Е.А. Тахо-Годи, В.П. Троицкого. М.: Время, 2002. Т. г. С. 106-230.

9 Тахо-Годи А.А., Тахо-Годи Е.А., Троиикий В.П. А.Ф. Лосев. Философ и писатель. М.: Наука, 2003. 395 с.

Iо Тахо-Годи Е.А. На пути к невесомости или в плену Содома // Лосев А.Ф. «Я сослан в XX век...»: в 2 т. / под ред. А.А. Тахо-Годи; сост. и коммент. А.А. Тахо-Годи, Е.А. Тахо-Годи, В.П. Троицкого. М.: Время, 2002. Т. г. С. 7-48. 
Тахо-Годи Е.А. Художественный мир прозы А.Ф. Лосева. М.: Большая Российская энциклопедия, 2007. 399 с.

\section{References}

I Kuznecov A. Uzrenie sushhestva muzyki pri posredstve estestva zhenskogo i bezumija artisticheskogo [Grasping the essense of music through femininity and artistic madness]. Available at: http://magazines.russ.ru/novyi_mi/r994/6/knobozo3.html (Accessed 28 March 20I6). (In Russ.)

2 Losev A.F. Zhenshhina-Myslitel' [The Woman-Thinker]. Losev A.F. “Ja soslan v XX vek...”: in $2 t$. [I am exiled in the $20^{\text {th }}$ century: in 2 vols.], ed. A.A. Taho-Godi; eds. And comment. A.A. Taho-Godi, E.A. Taho-Godi, V.P. Troitsky. Moscow, Vremja Publ., 2002, vol. 2, pp. 7-I4I. (In Russ.)

3 Losev A.F. Muzyka kak predmet logiki [Music as the subject of logic]. Losev A.F. Forma. Stil'. Vyrazhenie [Form. Style. Expression], ed. A.A. Taho-Godi; general ed. A.A. TahoGodi i I.I. Mahan'kov. Moscow, Mysl' Publ., I995, pp. 405-583. (In Russ.)

4 Losev A.F. O mirovozzrenii Eshila [On the worldview of Aeschylus]. Losev A.F. Forma. Stil'. Vyrazhenie [Form. Style. Expression], ed. A.A. Taho-Godi; general ed. A.A. TahoGodi i I.I. Mahan'kov. Moscow, Mysl' Publ., I995, pp. 78I-876. (In Russ.)

5 Losev A.F. Prilozhenie k romanu "Zhenshhina-myslitel'” [Appendix to the novel The Woman-Thinker]. Losev A.F. "Ja soslan $v$ XX vek...": in $2 t$. [I am exiled in the $2 \mathrm{O}^{\text {th }}$ century: in 2 vols.], ed. A.A. Taho-Godi; eds. and comment. A.A. Taho-Godi, E.A. Taho-Godi, V.P. Troitsky. Moscow, Vremja Publ., 2002, vol. 2, pp. I42-I62. (In Russ.)

6 Losev A.F. Russkaja filosofija [Russian philosophy]. Losev A.F. Na rubezhe jepoh: Raboty I9Io- $h$ - nachala I920- $h$ godov [On the turn of centuries: Works of the I9IOs-beginning of the I920s], general ed. and comment. A.A. Taho-Godi, E.A. Taho-Godi, V.P. Troitsky; eds. E.A. Taho-Godi, V.P. Troitsky. Moscow, Progress-Tradicija Publ., 2015, pp. I88-I89. (In Russ.)

7 Losev A.F. Stroenie hudozhestvennogo mirooshhushhenija [The structure of artistic worldview]. Losev A.F. Forma. Stil'. Vyrazhenie [Form. Style. Expression], ed. A.A. TahoGodi; general ed. A.A. Taho-Godi i I.I. Mahan'kov. Moscow, Mysl' Publ., I995, pp. 297-320. (In Russ.)

8 Losev A.F. Trio Chajkovskogo [Tchaikovsky trio]. Losev A.F. “Ja soslan v XX vek...”: in $2 t$. [I am exiled in the $20^{\text {th }}$ century], ed. A.A. Taho-Godi; eds. and comment. A.A. Taho-Godi, E.A. Taho-Godi, V.P. Troitsky. Moscow, Vremja Publ., 2002, pp. I06-230. (In Russ.)

9 Taho-Godi A.A., Taho-Godi E.A., Troickij V.P. A.F. Losev. Filosof i pisatel' [A.F. Losev. Philosopher and writer]. Moscow, Nauka Publ., 2003. 395 p. (In Russ.)

IO Taho-Godi E.A. Na puti k nevesomosti ili v plenu Sodoma [Towards zero grafity or indented by Sodom]. Losev A.F. “Ja soslan $v$ XX vek...”: in $2 t$. [I am exiled in the $20^{\text {th }}$ century: in 2 vols.], ed. A.A. Taho-Godi; eds. and comment. A.A. Taho-Godi, E.A. Taho-Godi, V.P. Troitsky. Moscow, Vremja Publ., 2002, vol. I, pp. 7-48. (In Russ.) Taho-Godi E.A. Hudozhestvennyj mir prozy A.F. Loseva [Losev's fictional world]. Moscow, Bol'shaja Rossijskaja jenciklopedija Publ., 2007. 399 p. (In Russ.) 